\title{
Lava y Cenizas: la Revolución Sandinista y el volcán de la solidaridad vasca
}

Yuridia Odalis Mendoza Duarte

Universidad Politécnica de Nicaragua, Nicaragua

ymendozad@gmail.com

Txema García, Lava y Cenizas: la Revolución Sandinista y el volcán de la solidaridad vasca, Elkar Argitaletxeak: Txertoa, 2019.

La Revolución Popular Sandinista, una lucha entre pasado y futuro ${ }^{1}$

$$
\begin{array}{r}
\text { No me pierdas con los políticos sanguinarios } \\
\text { en cuyos cartapacios no hay más que el crimen } \\
\text { y cuyas cuentas bancarias están hechas de sobornos } \\
\text { No me entregues al Partido de los hombres inicuos } \\
\text { iLibértame Señor! } \\
\text { Y bendeciré en nuestra comunidad al Señor } \\
\text { en nuestras asambleas } \\
\text { Ernesto Cardenal }
\end{array}
$$

Txema García Paredes, en Lava y cenizas: la Revolución Sandinista y el volcán de la solidaridad vasca 2009, invita a reflexionar sobre la última revolución del siglo XX en América Latina: la Revolución Popular Sandinista (RPS). El título es una referencia de la geografía nicaragüense, caracterizada por más de cincuenta estructuras volcánicas, y el texto ofrece un acercamiento periodístico mediante el cruzamiento de datos y la búsqueda de testimonios, con el objetivo

\footnotetext{
${ }^{1}$ Un agradecimiento muy especial al Dr. Oscar Fernando López Meraz por revisar esta reseña y por sus comentarios.

(c) () ()

Esta obra está protegida bajo una Licencia Creative Commons AtribuciónNo-Comercial 4.0 Internacional.
}

Secuencia. E-ISSN 2395-8464 http://secuencia.mora.edu.mx/

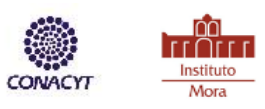


de sacar a la luz pública varias perspectivas sobre la revolución sandinista. El autor entrevistó a 18 figuras que ocuparon puestos claves durante la RPS, y hoy integran la oposición o el oficialismo, además de consultar a especialistas nicaragüenses y españoles para dar cuenta de narrativas varias. La obra también es producto de la experiencia del autor cuando fue brigadista en el país centroamericano en julio de 1983, unos días antes de la cuarta celebración del Aniversario del triunfo de la RPS.

El libro explica las diferentes etapas vividas por Nicaragua y el Frente Sandinista de Liberación Nacional (FSLN), desde su formación como movimiento de Liberación Nacional (a inicios de 1960) hasta convertirse tanto en partido de oposición (en la década de 1990) como en partido “atrapalotodo” en la actualidad, según la entrevista a Silvio Prado. Asimismo, observa la oposición de discursos, la división de miradas entre la utopía, la épica y la nostalgia, entre las brumas de la memoria y del presente, tiempo en la cual se han difumado los rastros originarios de una revolución que enfrentó diversos obstáculos como la guerra civil con los Contras $^{2}$ y la injerencia de la administración de Ronald Reagan en la década de 1980. En este sentido, el autor reflexiona sobre las dificultades que afrontó la RPS, con la finalidad de aportar diferentes matices y perspectivas sobre los procesos de cambio social.

Mediante la técnica de la entrevista estructurada, el autor accede a los recuerdos, experiencias, logros, sueños y obstáculos que vivieron estos actores durante la revolución. La recopilación de diferentes puntos de vista permite visualizar las problemáticas económicas, políticas y militares que conllevó este movimiento. García Paredes inicia con la participación

\footnotetext{
${ }^{2}$ Se le denominó a los elementos antisandinistas o Contras a las organizaciones que se conformaron en Honduras, Costa Rica y la zona de Zelaya norte y Zelaya central y sur. En Honduras se encontraba la Fuerza Democrática Nicaragüense (FDN), cuyo representante fue Enrique Bermúdez Varela; en Costa Rica, la Alianza Democrática Nicaragüense con Edén Pastora Gómez; en Zelaya norte Miskitos, Sumus, Ramas y Sandinistas Unidos (MISURATA), con Broolyn Rivera, y en Zelaya Central y Sur, la Unidad indígena de la Costa Caribe Nicaragüense (MISURA), al frente de Eduardo Pantín.

Secuencia. E-ISSN 2395-8464
} 
de figuras femeninas como Gloria Carrión, Gabriela Selser, Margaret Randall y Margarita Vaninni, jóvenes integrantes de la Cruzada Nacional de Alfabetización (CNA), y, en algunos casos, encargadas de instituciones oficiales como la correspondencia del periódico Barricada, la Asociación Sandinista de Trabajadores de la Cultura (ASTC) o el Instituto de Estudios del Sandinismos. Estas protagonistas destacan que en los primeros años de la revolución hubo logros sociales como la CNA, la reforma agraria y el acceso de la población a la salud, así como la educación gratuita universitaria.

Sin embargo, a raíz de la guerra civil con los Contras y la injerencia de la administración de Ronald Reagan, las actoras señalan que hubo cierta intolerancia a la crítica y el control de los medios de comunicación se agudizó. Por ejemplo, el periódico la Prensa sufrió censuras y retención de insumos, de igual forma la Agencia Nueva Nicaragua modificaba los titulares y cambiaba el sentido de muchos hechos en relación con los repliegues tácticos del EPS y los Contras. Existió, también, un control absoluto sobre las organizaciones de las mujeres, como la Asociación de Mujeres Nicaragüenses Luisa Amanda Espinoza (AMNLAE), vigilada por el FSLN.

En estas entrevistas, se menciona la doble moral de los miembros de la Dirección Nacional (DN) y del gabinete del FSLN, pues mientras los miembros de la DN vivían cómodamente en la década de 19980, la población puso los muertos y padeció los estragos del bloqueo económico impuesto por Reagan. En opinión de las entrevistadas, desde 1990 hasta el 2006 el sandinismo fue silenciado, y a partir del 2007 el FSLN personificó a Daniel Ortega como máximo líder del partido, además de apropiarse de la figura de Sandino.

Otras figuras que aparecen en el libro son Sergio Ramírez, Víctor Hugo Tinoco, Jaime Wheelock Román, Silvio Prado, José Luis de la Rocha Gómez, Gioconda Belli y Ernesto Cardenal, miembros del grupo denominado por el autor como "azul y blanco", opuesto al Secuencia. E-ISSN 2395-8464 
gobierno Sandinista, y nombrado así por ser los colores de las insignias en las manifestaciones de abril de 2018. ${ }^{3}$ Ellos reflexionan en torno a los logros de la RPS, como erradicación de la malaria, la polio, el sarampión y la tosferina; sin embargo, destacaron los errores de la revolución como la controversial "piñata”, el control excesivo sobre la producción campesina y cómo Daniel Ortega Saavedra -a partir de 2005- se adueñó del FSLN y se convirtió en el eterno candidato del partido.

En su mayoría, estas entrevistas señalan que Daniel Ortega Saavedra ha transmutado en una mafia al partido y que mediante el adoctrinamiento en las escuelas públicas se personifica al presidente como el máximo representante de FSLN. A través de una historia construida a modo, se muestra al público como su representante legítimo. Otra afirmación de este grupo es que la base social que respaldan a la figura presidencial gira alrededor del clientelismo político, cuyos máximos beneficiarios son servidores públicos, dirigentes pandilleros y la juventud sandinista.

"Rojo y negro" es la denominación que el autor le da a las figuras políticas que conforman actualmente el oficialismo del FSLN, como Carlos Fonseca Terán (hijo de Carlos Fonseca Amador, fundador del FSLN en 1963), Luis Barbosa y Edgardo García. Estos actores consideran que el presidente Daniel Ortega Saavedra y la vicepresidenta Rosario Murillo trabajan para el pueblo y que las manifestaciones de abril de 2018 por las reformas al Seguro Social fue un "golpe suave" auspiciado por la Iglesia, el Movimiento Renovador Sandinista (MRS), Estados Unidos y la empresa privada. En ningún momento critican el actuar de la

\footnotetext{
${ }^{3}$ El 18 de abril de 2018 ancianos y jóvenes universitarios se manifestaron en contra de las reformas de Seguridad Social impuesta por el presidente Sandinista Daniel Ortega Saavedra que aumentaba las contribuciones de trabajadores y empresarios e imponía una retención del 5\% a los jubilados. Según la Asociación Nicaragüense Pro-Derechos Humanos (ANDPH) se registraron 351 muertos debido a la represión de paramilitares y policías sandinistas.

${ }^{4}$ Se le denomino a la repartición de propiedades del Estado a miembros de la cúpula del FSLN en la década de 1990.

Secuencia. E-ISSN 2395-8464
} 
policía, el ejército y las acciones de violencia por parte de la Juventud Sandinista frente a las manifestaciones de los ancianos, jóvenes y madres que salieron a las calles en protesta por las reformas al seguro social. Estas figuras se comportan reacias al diálogo, pues consideran a los manifestantes golpistas y causantes tanto del declive económico como de los muertos, destacando jóvenes sandinistas, a quienes hicieron pasar como manifestantes de la oposición. De alguna manera, el discurso oficial de los entrevistados no es indiferente al poder institucional en donde cuestionar desde el interior es sumamente delicado y difícil.

Otro eje del libro es la violencia ejercida por la policía voluntaria y el ejército para quitar los tranques y reprimir a los que se manifestaron en abril de 2018. A pesar de que se creó una Comisión de la Verdad hay varios casos en los que no se han encontrado a los culpables de la muerte y desaparición de varios jóvenes. Los rojinegros resaltan los logros de la revolución como el 6\% del Presupuesto General de la República a las universidades, la CNA y los programas sociales que implementó el FSLN, a raíz de retomar el poder en el 2007, el Bono Productivo Alimentario para el campo, y Usura cero en la ciudad.

Las voces de los especialistas también fueron incorporadas Salvador Martí i Puig, Bernard Duterme, Manuel Ortega Hegg, Edmundo Mundo y Fernando Bárcenas, plantean que se ha desdibujado el carácter del FSLN como una formación política con liderazgo colectivo, y en su lugar prevalece un caudillismo que, con la cooperación de Alternativa Bolivariana para América Latina y el Caribe (ALBA), el comercio con Estados Unidos y el Fondo Monetario Internacional (FMI), ha duplicado el Producto Interno Bruto (PIB) durante la administración de Daniel Ortega Saavedra.

Finalmente, el autor le dedica un espacio muy breve a la solidaridad de Euskal Herria con la revolución Sandinista. Aporta un análisis sobre el proceso de creación de los Comités Internacionalistas, con el objetivo de tener una mayor coordinación y apoyar a la revolución a Secuencia. E-ISSN 2395-8464 
través de programas sociales y manifestaciones de rechazo a la política intervencionista de Reagan en los países de Centroamérica (El Salvador, Honduras, Guatemala y Nicaragua). A pesar de la Guerra Civil, el Comité vasco siempre estuvo presente, y a raíz del triunfo de Violeta Barrios de Chamarro se transformó en la cooperación para el desarrollo ligado a planes de desarrollo municipal porque sentía un vínculo con la revolución sandinista.

El libro tiene la virtud de servir para futuras investigaciones por contener información de primera mano, y ofrecer una crónica actualizada del FSLN y de la realidad nicaragüense. Una mirada abierta sobre un abanico amplio de temas. Por último, el autor señala que a raíz de las manifestaciones de abril de 2018 hay dos bandos en Nicaragua: uno que considera que las manifestaciones fueron "pacíficas”, y otro catalogado como un "golpe suave”. En este sentido, también afirma que aún prevalece una sociedad dividida en dos fuerzas: gobierno y oposición, y que ambas buscan la negación y la eliminación del otro. De la revolución sólo queda la utopía, y la esperanza de que surja una transformación más profunda que la RPS. 